\title{
"Wait, Go Back, I Might Miss Something Important!" Applying Leisure 101 to Simplify and Complicate BDSM
}

\author{
D J Williams, $\mathrm{PhD}$ \\ Idaho State University \\ Center for Positive Sexuality (Los Angeles) \\ Emily E. Prior, MA \\ College of the Canyons \\ Center for Positive Sexuality (Los Angeles)
}

Recently, there seems to be heightened discussion among academics and clinicians about what, theoretically, BDSM is. Historically, BDSM has long been understood from a psychopathological perspective as categorized by Richard von Krafft-Ebing (1886/1978) and further reified by Freud (1905/1953). Despite popular explanations of BDSM participation from a psychopathological perspective, a rapidly accumulating scholarly literature has severely discredited this perspective (for reviews, see Powls \& Davies, 2012; Sandnabba, et al., 2002; Weinberg, 2006; Williams, 2006; 2013).

BDSM is also commonly interpreted from discourses focusing directly on sexuality, yet such an approach is limited given that many BDSM participants do not experience BDSM activities as being a part of sexual interaction (Dancer, Kleinplatz, \& Moser, 2006; Newmahr, 2010). In fact, new research by Sloan (2015) found that some people with asexual identities are attracted to BDSM participation as a means of forming intimate, but nonsexual, relationships. In a somewhat different theoretical twist, Simula (2015) found in her research that a small percentage of people seemed to experience BDSM as a particular orientation, thus she suggested that traditional understandings of sexual orientation should be expanded.

Scholars recognize that BDSM is extremely complex and that existing explanations are, and perhaps always will be, incomplete. However, in considering the many academic and nonacademic accounts of BDSM, our focus in this paper is to suggest that a broad leisure perspective currently offers the best theoretical approach to begin making sense of BDSM. We will briefly discuss scholarship on BDSM as potential serious or casual leisure before then backtracking a bit to redirect focus on BDSM as leisure, more broadly.

\section{Continuum of Casual to Serious Leisure}

Leisure activities are often classified as being more or less casual or serious leisure according to a continuum, with casual leisure at one end and serious leisure at the other. Scholars have documented that BDSM seems to qualify as serious leisure (Newmahr, 2010; Williams, 2006, 2009), based on the concept and criteria for serious leisure developed by Stebbins (1999, 2007). Stebbins' criteria for serious leisure are: requires perseverance; requires the acquisition of specialized knowledge, training, and skill; the leisure pursuit is career-like; the activity has durable benefits and rewards; participants identify with the leisure activity; and the leisure pursuit is associated with a unique ethos. 
In contrast to BDSM as serious leisure, Prior and Williams (2015) found in a small, exploratory study of female participants that BDSM reflected attributes of what Stebbins (1997) described as casual leisure which, in contrast to serious leisure, is spontaneous, short-lived, playful, and does not require specialized skill. Furthermore, BDSM participants in other studies have sometimes used terms consistent with casual leisure to describe their BDSM experiences, such as "fun," "playful," "escape from ordinariness of life," "being yourself," and "freedom from day-to-day roles" (Hebert \& Weaver, 2015; Taylor \& Ussher, 2001).

Stebbins (2007) has also described "project-based" leisure, which he defined as a one-time, or occasional creative undertaking that occurs during free-time. Project-based leisure requires considerable planning and has elements of serious and casual leisure, and may include hosting events or fundraising activities.

These observations generate several interesting questions for leisure scholars: Is BDSM primarily serious leisure or casual leisure? Is it an interesting mixture of both? Or, is it sometimes more or less of one of the other at different times? Or does it vary according to specific BDSM identities or perhaps moderated by demographic variables? Specific events, such as fundraising efforts for charities that are hosted by BDSM communities can be understood as project-based leisure.

While the above questions are provocative for scholars, the possibility that BDSM may at times be both serious and casual leisure, and specific events sometimes may be understood as projectbased leisure, is a strong reminder that, for practical purposes, it may more helpful, at least for now, to refocus on the concept and many attributes of leisure more broadly. Leisure itself, along with the field of leisure science, is not well understood among non-academics and leisure is often assumed by many to be simple free time. Curiously, too, is the fact that although scholars have discussed BDSM in terms of serious or casual leisure, little discussion has been devoted to BDSM as leisure in a much more general sense. In short, we may have missed the expansive forest due to our focus on a few select trees.

\section{Back to Basics: Leisure 101 and BDSM}

\section{Common Definitional, Conceptual, and Theoretical Issues}

Leisure is often interpreted by lay people as a rather simplistic concept, yet leisure scholars do not agree on a precise definition or the ways to best measure it. Leisure experience may be approached as activity, setting, or time, and thus can be studied as behavior, setting (context), or psychological state (Kleiber, et al. 2011). Because leisure can be approached in such different ways, leisure science, in addition to being its own unique field, also draws from several relevant fields and disciplines, including sociology, social psychology, anthropology, biology, and health sciences (see Walker, et al. in press/2015). Not surprisingly, leisure also applies a variety of theories that are found in other social and behavioral sciences, including classic psychological and macro sociological theories. Leisure scholars also utilize robust contemporary theories that are particularly well-suited for exploring leisure subject matter, such as self-determination theory (Deci \& Ryan, 1985) and flow theory (Csikszentmihalyi \& Csikszentmihalyi, 1988). Constraint 
theory (Jackson, 2005) is specific to leisure and focuses on intrapersonal, interpersonal, and structural barriers that prevent people from experiencing desired leisure.

Leisure preferences have strong roots in one's biological make-up and early socialization experiences and are also shaped by the social environment and situational influences (Iso-Ahola, 1980). Several leisure scholars have applied the "Big Five" personality factor model (McCrae \& Costa, 1999), which includes dimensions of extroversion, agreeableness, conscientiousness, neuroticism, and openness to experience, to help explain individuals' leisure preferences (Kleiber, et al., 2011). Interestingly, Wismeijer and van Assen (2013) recently assessed psychological functioning of BDSM practitioners via the "Big Five" model and subsequently suggested that BDSM did not fit a psychopathological perspective but instead seemed to be a form of "recreational leisure" (p. 1951).

Although scholars do not agree on a precise definition of leisure, there is a consensus that leisure experience must be intrinsically motivated, freely chosen, and thus personally meaningful. There is an incredibly wide range of potential activities, both personal and social, that if freely chosen and intrinsically motivated, can qualify as legitimate leisure, including all sorts of hobbies, artistic endeavors, cultural events, sports, outdoor activities, and social activities. The possibilities for leisure are seemingly endless. There are, of course, also a wide range of diverse potential activities that fall under the umbrella of BDSM.

As with common leisure, BDSM scholars recognize that while there have been well-known descriptions of BDSM (i.e., Weinberg, et al. 1984) a precise definition has remained elusive (Moser \& Kleinplatz, 2006). Also like leisure, generally, BDSM is often approached as freely chosen, genuinely desired and intrinsically motivated activity, yet BDSM can also be approached primarily as play time or space (setting). Experts and participants alike recognize the multidisciplinary approach that is necessary in attempting to understand BDSM phenomena, including knowledge of the biological, psychological, and social forces that impact personal desires, motivations, and meanings. When considering basic definitional, conceptual and multidisciplinary commonalities, BDSM is strikingly consistent with leisure.

\section{Common Leisure Properties and Benefits}

Leisure scholars have discussed common properties associated with diverse forms of leisure experience, including a sense of personal freedom; positive feelings, such as adventure, excitement, fun, happiness, pleasure or enjoyment; sense that time is altered (participants often feel like time has passed more quickly than actual clock time); and reduced stress or relaxation (Kleiber, et al. 2011). Participants in BDSM research frequently describe these same leisure properties experienced in their BDSM play (i.e., Hebert \& Weaver, 2015; Prior \& Williams, 2015; Taylor \& Ussher, 2001; Weiss, 2015).

Indeed, leisure is associated with positive physical and psychological benefits and is thus therapeutic (for reviews, see Caldwell, 2005; Mannell, 2007). BDSM also seems to be therapeutic for the same reasons, and there are three chapters devoted to the therapeutic possibilities of BDSM participation in the edited collection Safe, Sane and Consensual (Langdridge \& Barker, 2007). Regarding professional BDSM, Lindemann (2011) reported that 
dominatrices understand their occupation as providing a unique form of psychological therapy to clients, while Williams and Storm (2012) described commonalities of professional BDSM with other helping professions, including leisure education / therapeutic recreation and psychotherapy. Also, scholars have also found that leisure is frequently a salient part of one's overall identity (Kleiber, et al. 2011), and research suggests that leisure can promote personal growth, transcendence, and personal transformation (Kleiber, et al. 2002). Personal growth and transcendence are common themes found in research on BDSM experience (i.e., Hebert \& Weaver, 2015; Taylor \& Ussher, 2001). Personal growth is specifically mentioned along with erotic arousal, naturally linked with pleasure (another common leisure attribute), in Jay Wiseman's (1996) classic definition of BDSM:

(BDSM is) the knowing use of psychological dominance and submission, and/or physical bondage, and/or pain, and/or related practices in a safe, legal, and consensual manner in order for the participants to experience erotic arousal and/or personal growth (p. 10). It appears from this definition that BDSM is a form of legitimate leisure activity.

\section{Conclusion}

Words like "play," "fantasy," "games," and "toys" are ubiquitous in the language of BDSM-so much so that their meanings and theoretical implications are assumed to be self-evident. Such words are rarely, if ever, defined in BDSM texts, yet these are the focus of leisure science. At the same time, scholars have casually noted that BDSM may be a form of recreational leisure (Weiss, 2015, Wismeijer \& van Assen, 2013) and a few have focused directly on BDSM as casual or serious leisure, specifically (Newmahr, 2010; Prior \& Williams, 2015; Williams, 2006, 2009). However, it seems that in our preoccupation with casual or serious leisure, we have skipped past many of the basics of leisure more broadly. By refocusing on the basics of leisure, generally, non-academics may gain a better understanding of how and why BDSM functions as attractive leisure for very large numbers of people. For scholars, this return to "Leisure 101" can stir interesting new questions. Perhaps more importantly, it can help connect BDSM researchers who may be unfamiliar with leisure science with curious leisure scholars who are unfamiliar with BDSM research. In discussing the future of leisure science, Stebbins (2011) noted that leisure is the "happy science" with much to contribute, and thus it needs to expand into other disciplines and practices. We hope that this short paper is sufficiently provocative to encourage scholars and professionals to build more bridges across disciplines and occupations.

BDSM seems to fit very nicely within a broad leisure framework, which accounts for sexuallymotivated BDSM (sexual activities can be a form of leisure), but a leisure perspective also helps explain desired BDSM practices that are not experienced as sexual or erotic. Leisure scholars focus on what, when, why, how, and for whom freely chosen and intrinsically motivated experiences are meaningful and enjoyable to various individuals, and scholars recognize the complexity and diversity of leisure practices. Additionally, considering BDSM as a specific orientation or identity is not at all in opposition to a leisure approach, and there is considerable leisure science that addresses leisure as it relates to gender, sexual minorities, age, culture, and other demographic variables.

There are undoubtedly some cases where people consensually participate in BDSM, but their participation is instrumental and not intrinsically motivated or particularly enjoyable. For 
example, there may be cases where agreed-upon participation occurs due to compromise from a romantic partner. Such cases can be of interest from a leisure perspective through questions of lifestyle and activity selection, perhaps including how and why these people devote time in ways that they do. However such indifferent or extrinsically motivated experience itself, though consensual but not freely chosen, probably does not qualify as genuine leisure experience for that individual. Nevertheless, in considering both the material of leisure science and the broad literature on BDSM, a general leisure framework seems to offer a cohesive, yet sufficiently flexible, perspective for understanding and exploring the complexities of BDSM.

Caldwell, L. L. (2005). Leisure and health: Why is leisure therapeutic? British Journal of Guidance and Counseling, 33, 7-26.

Csikszentmihalyi, M., \& Csikszentmihalyi, I. (1988, Eds.) Optimal experience: Psychological studies of flow in consciousness. New York: Cambridge University Press.

Dancer, P., Kleinplatz, P. J., \& Moser, C. (2006). 24/7 SM slavery. Journal of Homosexuality, 50(2/3), 81-101.

Deci, E. L., \& Ryan, R. A. (1985). Intrinsic motivation and self-determination in human behavior. New York: Plenum Press.

Freud, S. (1905/1953). Three essays on sexuality. The standard edition of the complete psychological works of Sigmund Freud, Vol. 7. London: Hogarth Press.

Hebert, A., \& Weaver, A. (2015). Perks, problems, and the people who play: A qualitative exploration of dominant and submissive BDSM roles. Canadian Journal of Human Sexuality, 24, 49-62.

Iso-Ahola, S. E. (1980). The social psychology of leisure and recreation. Dubuque, IA: William C. Brown Company.

Jackson, E. L. (2005, Ed.). Constraints to leisure. State College, PA: Venture.

Kleiber, D. A., Hutchinson, S., \& Williams, R. (2002). Leisure as a resource in transcending negative life events: Self-protection, selfrestoration and personal transformation. Leisure Sciences, 24, 219-235.

Kleiber, D. A., Walker, G. J., \& Mannell, R. C. (2011). A social psychology of leisure $\left(2^{\text {nd }}\right.$ edi.). State College, PA. Venture.

Langdridge, D., \& Barker, M. (2007, Eds.). Safe, sane and consensual: Contemporary perspectives on sadomasochism. New York: Palgrave-Macmillan.

Lindemann, D. (2011). BDSM as therapy? Sexualities, 14, 151-172.

Mannell, R. C. (2007). Health, well-being and leisure. World Leisure Journal, 49, 114-128.

\section{References}

McCrae, R. R., \& Costa, P. T. (1999). A five-factor theory of personality. In L. A. Pervin \& O. P. John (Eds.), Handbook of personality: Theory and research (pp. 139-153). New York: Academic Press.

Moser, C., \& Kleinplatz, P. J. (2006). Introduction: The state of our knowledge on SM. Journal of Homosexuality, 50(2/3), 1-15.

Newmahr, S. (2010). Rethinking kink: Sadomasochism as serious leisure. Qualitative Sociology, 33, 313-333.

Powls, J., \& Davies, J. (2012). A descriptive review of research relating to sadomasochism: Considerations for clinical practice. Deviant Behavior, 33, 223-234.

Prior, E. E., \& Williams, D J (2015). Does BDSM power exchange among women reflect casual leisure? An exploratory qualitative study. Journal of Positive Sexuality, 1, 1215.

Sandnabba, N. K., Santilla, P., Alison, L., \& Nordling, N. (2002). Demographics, sexual behavior, family background and abuse experiences of practitioners of sadomasochistic sex: A review of recent research. Sexual and Relationship Therapy, $17,39-55$

Simula, B. (2015). "Give me a dominant of any gender over any kind of non-dominant": Sexual orientation beyond gender. In T. S. Weinberg \& S. Newmahr (Eds.), Selves, symbols, and sexualities: An interactionist anthology (pp. 163-177). Los Angeles: Sage.

Sloan, L. J. (2015). Ace of (BDSM) clubs: Building asexual relationships through BDSM practice. Sexualities (online advance access).

Stebbins, R. A. (1997). Casual leisure: A conceptual statement. Leisure Studies, 16, 17-25.

Stebbins, R. A. (1999). Serious leisure. In E. L. Jackson \& T. L. Burton (Eds.), Leisure studies: Prospects for the Twenty-First Century. State College, PA: Venture. 
Stebbins, R. A. (2007). Serious leisure: A perspective for our time. Piscataway, NJ: Transaction.

Stebbins, R. A. (2011). Leisure studies: The road ahead. World Leisure Journal, 53, 3-10.

Taylor, G. W., \& Ussher, J. M. (2001). Making sense of S\&M: A discourse analytic account. Sexualities, 4, 293-314.

von Krafft-Ebing, R. (1886/1978). Psychopathia sexualis. New York: Stein \& Day/Scarborough.

Walker, G. J., Scott, D., \& Stodolska, M. (in press). Leisure matters: The state and future of leisure studies. State College, PA: Venture.

Weinberg, M., Williams, C. J., \& Moser, C. (1984). The social constituents of sadomasochism. Social Problems, 31, 379-393.

Weinberg, T. S. (2006). Sadomasochism and the social sciences: A review of the sociological and social psychological literature. Journal of Homosexuality, 50(2/3), 17-40.

Weiss, M. (2015). BDSM. In P. Whelehan \& A. Bolin (Eds.), The international encyclopedia of human sexuality. New York: John Wiley $\&$ Sons.
Williams, D J (2006). Different (painful!) strokes for different folks: A general overview of sexual sadomasochism and its diversity. Sexual Addiction and Compulsivity, 13, 333346.

Williams, D J (2009). Deviant leisure: Rethinking "the good, the bad, and the ugly." Leisure Sciences, 31, 207-213.

Williams, D J (2013). Social work, BDSM, and vampires: Toward understanding and empowering people with non-traditional identities. Canadian Social Work, 15, 10-24.

Williams, D J, \& Storm, L. E. (2012). Unconventional leisure and career: Insights into the work of professional dominatrices. Electronic Journal of Human Sexuality, volume 12 (online).

Wiseman, J. (1996). SM101: A realistic introduction. San Francisco, CA: Greenery Press.

Wismeijer, A.A.J., \& van Assen, M.A.L.M. (2013). Psychological characteristics of BDSM practitioners. Journal of Sexual Medicine, 10, 1943-1952. 